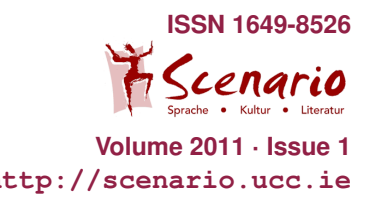

Stimmen aus der Praxis - Practitioners' Voices

\title{
Ein Gespräch mit der Leiterin von Wortspiel-Berlin, Sigrid Unterstab
}

Seit 2007 existiert Wortspiel-Berlin, ein Projekt der Sprachlehrerin und Theaterpädagogin Sigrid Unterstab, in dem um es um die Förderung von kreativen Sprachlehr-/lernmethoden geht. Wortspiel-Berlin bietet Fortbildungsseminare für Sprachlehrerende an, Theaterkurse für verschiedene Zielgruppen und auch Individualunterricht. Detailliertere Informationen finden sich unter: http://www.wortspiel-berlin.de

SCENARIO wird gelegentlich auf derartige Initiativen im Praxisfeld aufmerksam machen, um dadurch auf Fortbildungsmöglichkeiten hinzuweisen und die Bildung von Netzwerken zu fördern.

Sigrid Unterstab wurde am 18.5. 2011 in Berlin von Manfred Schewe interviewt.

Das Interview kann hier herunter geladen werden. 